\title{
Correction to: A consensus response on the complete picture: reply to Lynøe and Eriksson
}

Arabinda Kumar Choudhary ${ }^{1}$ (D) S Sandeep K. Narang ${ }^{2}$. Joëlle Anne Moreno ${ }^{3}$. Cindy W. Christian ${ }^{4}$. Sabah Servaes ${ }^{5}$. Vincent J. Palusci ${ }^{6}$. Gary L. Hedlund ${ }^{7,8,9} \cdot$ Mark S. Dias $^{10} \cdot$ Marvin D. Nelson ${ }^{11}$ • V. Michelle Silvera ${ }^{12}$. Susan Palasis ${ }^{13,14} \cdot$ Maria Raissaki $^{15} \cdot$ Andrea Rossi $^{16} \cdot$ Amaka C. Offiah ${ }^{17,18,19}$

Published online: 16 March 2019

(C) Springer-Verlag GmbH Germany, part of Springer Nature 2019

Correction to: Pediatric Radiology (2019) 49:424-428 https://doi.org/10.1007/s00247-019-04341-4

The original version on this paper contained an error. The COI statement is incorrectly presented. The correct statement is presented below:

Conflicts of interest Drs. Narang, Palusci and Hedlund have been paid as expert consultants in cases of suspected abusive head trauma. Drs. Choudhary, Christian, Servaes, Nelson, Palasis, Rossi and Offiah provide medical-legal expert work in child abuse cases.

Publisher's note Springer Nature remains neutral with regard to jurisdictional claims in published maps and institutional affiliations.

The online version of the original article can be found at https://doi.org/ 10.1007/s00247-019-04341-4

Arabinda Kumar Choudhary

ac0026@nemours.org

Extended author information available on the last page of the article 


\section{Affiliations}

\section{Arabinda Kumar Choudhary ${ }^{1}$ (D) - Sandeep K. Narang ${ }^{2}$ • Joëlle Anne Moreno ${ }^{3}$. Cindy W. Christian ${ }^{4} \cdot$ Sabah Servaes $^{5}$. Vincent J. Palusci ${ }^{6}$. Gary L. Hedlund ${ }^{7,8,9} \cdot$ Mark S. Dias $^{10} \cdot$ Marvin D. Nelson $^{11} \cdot$ V. Michelle Silvera ${ }^{12} \cdot$ Susan Palasis ${ }^{13,14}$. Maria Raissaki ${ }^{15} \cdot$ Andrea Rossi $^{16} \cdot$ Amaka C. Offiah ${ }^{17,18,19}$}

1 Department of Radiology,

Nemours/Alfred I. duPont Hospital for Children,

1600 Rockland Road,

Wilmington, DE 19803, USA

2 Child Abuse Pediatrics,

Ann \& Robert H. Lurie Children's Hospital of Chicago,

Chicago, IL, USA

3 Florida International University College of Law,

Miami, FL, USA

4 Department of Pediatrics, Child Abuse and Neglect Prevention,

The Children's Hospital of Philadelphia,

The Perelman School ofMedicine at The University of Pennsylvania, Philadelphia, PA, USA

5 Department of Radiology, The Children's Hospital of Philadelphia, University of Pennsylvania,

Philadelphia, PA, USA

6 New York University School of Medicine,

New York, NY, USA

7 Department of Medical Imaging,

Primary Children's Hospital,

Salt Lake City, UT, USA

8 Department of Radiology,

Intermountain Healthcare,

Salt Lake City, UT, USA

9 University of Utah School of Medicine,

Salt Lake City, UT, USA

10 Departments of Neurosurgery and Pediatrics,

Penn State Health Children's Hospital,

Hershey, PA, USA
11 Department of Radiology,

Children's Hospital of Los Angeles,

Los Angeles, CA, USA

12 Department of Radiology,

Boston Children's Hospital,

Boston, MA, USA

13 Pediatric Neuroradiology,

Children's Healthcare of Atlanta,

Scottish Rite Campus, Atlanta, GA, USA

14 Department of Radiology,

Emory University School of Medicine,

Atlanta, GA, USA

15 Department of Radiology,

University Hospital of Heraklion, University of Crete, Crete, Greece

16 Neuroradiology Unit, Istituto Giannina Gaslini Children's Hospital, Genoa, Italy

17 Paediatric Musculoskeletal Imaging, Academic Unit of Child Health, Sheffield, UK

18 Sheffield Children's NHS Foundation Trust, Western Bank, Sheffield, UK

19 University of Sheffield, Sheffield, UK 